\title{
ОТОРИНОЛАРИНГОЛОГИЯ
}

УДК 616.211-002-08:615.03:547.96

\author{
А. А.Завалий, А. В. Кубышкин, А. А. Жукова
}

ВЛИЯНИЕ МУКОАКТИВНЫХ ПРЕПАРАТОВ НА СОСТОЯНИЕ НЕСПЕЦИФИЧЕСКИХ ПРОТЕИНАЗ И ИХ ИНГИБИТОРОВ У БОЛЬНЫХ ОСТРЫМ КАТАРАЛЬНЫМ РИНОСИНУСИТОМ

Медицинская академия им. С. И. Георгиевского Крымского федерального университета им. В. И. Вернадского, Республика Крым, 295006, Симферополь, бул. Ленина, 5/7

Исследование проведено у трех групп больных (45 человек) острым катаральным риносинуситом с применением в комплексе лечения мукоактивных препаратов. Установлено, что данная патология характеризуется острофазным повышением антитрипсиновой активности в сыворотке крови и в синоназальном секрете. При сравнительном анализе результатов применения мукоактивных препаратов различных групп показано, что при данной форме воспаления терапевтический эффект выше, если использовать препарат BNO-101, который на фоне нормализации клинических симптомов приводил к снижению активности эластазо- и трипсиноподобных протеаз, а также к нормализации активности ингибиторов протеиназ в синоназальном секрете. Библиогр. 12 назв. Табл. 1.

Ключевые слова: острое катаральное воспаление, риносинусит, мукоактивные препараты, неспецифические протеиназы, ингибиторы неспецифических протеиназ.

\section{THE INFLUENCE OF MUCOACTIVE AGENTS ON THE STATE OF NON-SPECIFIC PROTEINASES AND THEIR INHIBITORS IN PATIENTS WITH ACUTE CATARRHAL RHINOSINUSITIS}

\section{A. A.Zavalii, A. V.Kubyshkin, A. A.Zhukova}

S. I. Georgievsky Medical Academy of V.I. Vernadsky Crimean Federal University, Republic of Crimea, 295006, Simferopol, Lenina bul., 5/7

The study was conducted in three groups of patients (45 subjects) with acute catarrhal rhinosinusitis using mucoactive agents as a part of treatment. It has been established that this pathology is characterized by an acute-phase increase of antitrypsin activity in the blood serum and sinonasal discharge. Comparative analysis of the results obtained after applying various groups of mucoactive agents has demonstrated that BNO-101 has greater effect in this type of inflammation; it decreased the activity of elastase and trypsin-like proteases while normalizing clinical symptoms and the activity of proteinase inhibitors in the sinonasal discharge. Refs 12. Table 1.

Keywords: acute catarrhal inflammation, rhinosinusitis, mucoactive agents, proteinases, proteinase inhibitors.

(C) Санкт-Петербургский государственный университет, 2016 


\section{Введение}

Острые риносинуситы (РС) являются одной из наиболее частых патологий, развивающихся на фоне острой респираторной инфекции. По данным D. C. Shield, у 87 \% пациентов с симптомами простуды были обнаружены патологические изменения слизистой как минимум одного из параназальных синусов [1]. Как правило, взрослые переносят 2-3 эпизода, а дети - до 10 эпизодов острых респираторных заболеваний в год [2]. Следует отметить, что в России острым риносинуситом в течение года заболевают около 10 млн человек, а в целом до $15 \%$ взрослого населения Земли страдают различными формами синусита $[1,2,3]$.

Острый РС сопровождается отеком слизистой оболочки, транссудацией плазмы, гиперсекрецией желез, застоем секрета и нарушением воздухообмена в околоносовых пазухах. При этом нарушается функция мукоцилиарной транспортной системы (МЦТС), что приводит к продлению времени контакта патогенных бактерий с клетками слизистой оболочки [4]. В условиях выраженного отека, блокады естественного соустья, застоя секрета и снижения парциального давления кислорода в пазухах без своевременного и адекватного лечения создаются оптимальные условия для развития бактериальной инфекции $[5,6]$.

Логично предположить, что рациональное применение мукоактивных препаратов будет способствовать восстановлению функции МЦТС за счет нормализации реологических свойств секрета и восстановления проходимости носовых ходов, соустий околоносовых пазух. Это патогенетические основы, необходимые для лечения воспалительного процесса в слизистой оболочке верхних дыхательных путей. В связи с этим изучение эффективности применения мукоактивных препаратов при риносинуситах является актуальной задачей.

Целью исследовательской работы было определение влияния мукоактивных препаратов разных групп на состояние протеолитической и антипротеиназной активности в сыворотке крови и синоназальном секрете при лечении больных с острым катаральным риносинуситом.

\section{Материалы и методы}

Было пролечено 45 больных острым катаральным РС. Развитие РС больные связывали с начавшимся ранее ОРВИ.Из 45 человек у 13 больных (28,9\%) признаки острого РС появились на 4-й день болезни, у 18 человек (40\%) - на 5-й день, у $14(31,1 \%)$ - на 7-й день. Диагноз устанавливали на основании общеклинического и оториноларингологического обследования больных. Оценивали общее состояние, в том числе повышение температуры тела выше $37,2{ }^{\circ} \mathrm{C}$; наличие и степень выраженности следующих симптомов: головная боль, чувство тяжести в проекции пазух, наличие слизистых выделений из носа, затруднение носового дыхания, гипосмия; отек слизистой оболочки полости носа и состояние средних носовых ходов при эндоскопическом осмотре. Также учитывали данные лучевой диагностики околоносовых пазух.

Материалом для исследования являлась сыворотка крови и синоназальный секрет больных острым катаральным РС. Периферическую кровь брали из локтевой вены, синоназальный секрет получали абсорбционным методом в модификации [7, 
$8,9]$. Пинцетом в средний носовой ход каждой половины полости носа помещали полоску 0,5×1,0 см стерильного губчатого тампона из поливинилацетата на 15 минут. Физико-химические свойства этого материала обусловливают увеличение тампона в объеме в присутствии жидкости. После удаления тампон выжимали пинцетом в пробирку с 1 мл физиологического раствора. Раствор центрифугировали при 1000 об/мин в течение 15 минут для осаждения клеток и слизи. В надосадочной жидкости исследовали показатели активности протеиназ и их ингибиторов [10].

Лечение в группах проводилось согласно стандартам и включало мукоактивные, нестероидные противовоспалительные, антигистаминные, а также противоотечные препараты. Местно применялись назальные деконгестанты. Оториноларингологический осмотр проводили ежедневно. Курс лечения составил 7 дней.

Пациенты были разделены на группы в зависимости от применяемого мукоактивного препарата: в 1-й группе $(\mathrm{n}=11)$ применяли $\mathrm{N}$-ацетилцистеин (АЦЦ) механизм его действия связан с разрывом бисульфидных связей кислых мукополисахаридов патологического секрета благодаря наличию в молекуле препарата свободной сульфгидрильной группы. За счет этого наблюдается уменьшение вязкости секрета и улучшается работа МЦТС.

Во 2-й группе ( $\mathrm{n}=11)$ - S-карбоксиметилцистеин (КМЦ) - обладает одновременно как муколитическим, так и мукорегулирующим эффектом. Как муколитик он уменьшает вязкость и тягучесть секрета мерцательного эпителия, обеспечивая его экспекторацию, а как мукорегулятор - увеличивает синтез сиаломуцинов. Механизм действия карбоцистеина связан с активацией сиаловой трансферазы фермента бокаловидных клеток слизистой оболочки дыхательных путей. Также под действием карбоцистеина происходят регенерация слизистой оболочки, восстановление ее структуры, уменьшение и нормализация количества бокаловидных клеток.

В 3-й группе ( $\mathrm{n}=13)$ применяли растительный фитониринговый препарат (BNO-101) «Синупрет». Он регулирует секрецию, нормализует вязкость слизи, устраняет мукостаз, тем самым восстанавливая мукоцилиарный клиренс. Снижение вязкости секрета происходит за счет стимуляции секреторных клеток слизистой оболочки, вырабатывающих нейтральные мукополисахариды. Регуляция секреции осуществляется афферентным парасимпатическим путем (вагусный гастропульмональный рефлекс). Кроме того, препарат оказывает противоотечное и противовоспалительное воздействие на слизистую оболочку; способствует восстановлению дренажной и вентиляционной функции околоносовых пазух [11].

Контрольную группу составили больные с острым катаральным РС ( $\mathrm{n}=10)$, которые в комплексе лечения мукоактивные препараты не получали. Показатели нормы определяли у 12 здоровых волонтеров.

Взятие материала проводили до начала лечения, на третий и седьмой день лечения. Для оценки выраженности воспалительного процесса в динамике исследовали протеиназ-ингибиторную активность в сыворотке крови и в синоназальном секрете [10]. Эластазоподобую активность (ЭПА) определяли по скорости ферментативного гидролиза синтетического субстрата N-T-бок-L-аланил-п-нитрофенилового эфира (BANPE), трипсиноподобную активность (ТПА) - по скорости отщепления бензоил-аргинина от N-a-бензоил-L-аргинин-этилового эфира (BAEE), антитриптическую активность (АТА) и кислотостабильные ингибиторы (КСИ) - по 
торможению биологическим материалом ферментативного гидролиза трипсином BAEЕ. Полученные результаты определения показателей в синоназальном секрете пересчитывали на 1 г общего белка, который определяли методом Лоури [12].

Статистическую обработку проводили методами вариационной статистики с использованием критерия достоверности Стьюдента и достоверными считали различия показателей при $\mathrm{p}<0,05$.

\section{Результаты и их обсуждение}

Как показало проведенное исследование, у всех пациентов с РС в сыворотке крови и синоназальном секрете отмечалась реакция, характерная для острой фазы воспалительного процесса. Так, в сыворотке на фоне незначительного повышения эластазоподобной активности отмечались довольно существенное повышение активности трипсиноподобных протеиназ по отношению к контролю и достоверный острофазный рост антитрипсиновой активности на $20 \%$ (р<0,05).

Более специфичные изменения в состоянии неспецифических протеиназ и их ингибиторов отмечены при исследовании синоназального секрета, что нашло отражение в таблице. У больных катаральным риносинуситом почти в 2 раза повысилась ЭПА, более чем в 1,5 раза - ТПА. На этом фоне отмечено компенсаторное повышение ингибиторного потенциала. Например, уровень АТА увеличился на $16,8 \%$ в сыворотке и на 90,9\% в синоназальном секрете, КСИ в крови возрос на $18,6 \%$, в секрете - на $71,2 \%$.

Динамика показателей протеиназ-ингибиторной системы в синоназальном секрете при лечении больных острым катаральным риносинуситом

\begin{tabular}{|l|c|c|c|c|c|c|}
\hline \multicolumn{1}{|c|}{$\begin{array}{c}\text { Группа } \\
\text { наблюдения }\end{array}$} & $\begin{array}{c}\text { Период } \\
\text { исследования }\end{array}$ & $\begin{array}{c}\text { ЭПА, } \\
\text { нмоль/мг }\end{array}$ & $\begin{array}{c}\text { ТПА, } \\
\text { мкмоль/мг }\end{array}$ & $\begin{array}{c}\text { AТА, } \\
\text { ИЕ/мг }\end{array}$ & $\begin{array}{c}\text { КСИ, } \\
\text { ИЕ/мг }\end{array}$ & $\begin{array}{c}\text { Белок, } \\
\text { мг/л }\end{array}$ \\
\hline Норма (n=12) & - & $3,25 \pm 0,95$ & $3,46 \pm 0,76$ & $156,4 \pm 30,1$ & $217,2 \pm 26,3$ & $154,4 \pm 23,1$ \\
\hline $\begin{array}{l}\text { Все больные } \\
(\mathrm{n}=45)\end{array}$ & До лечения & $6,18 \pm 1,08^{*}$ & $5,20 \pm 0,57^{*}$ & $298,6 \pm 42,1^{*}$ & $372,0 \pm 83,0$ & $248,0 \pm 36,8$ \\
\hline $\begin{array}{l}\text { Контрольная } \\
(\mathrm{n}=10)\end{array}$ & 3 -й день & $5,68 \pm 0,86^{*}$ & $5,3 \pm 0,46^{*}$ & $256,2 \pm 41,1^{*}$ & $334,5 \pm 78,1$ & $254,6 \pm 35,2^{*}$ \\
\cline { 2 - 7 } & 7 -й день & $4,85 \pm 0,79$ & $4,78 \pm 0,43$ & $212,1 \pm 40,9$ & $298,1 \pm 75,0$ & $232,3 \pm 31,6^{*}$ \\
\hline \multirow{2}{*}{ АЦЦ (n =11) } & 3 -й день & $5,90 \pm 0,91^{*}$ & $5,11 \pm 0,39^{*}$ & $264,8 \pm 41,2^{*}$ & $326,2 \pm 74,6$ & $242,1 \pm 33,1^{*}$ \\
\cline { 2 - 7 } & 7 -й день & $5,12 \pm 0,88$ & $4,72 \pm 0,31$ & $245,3 \pm 40,5$ & $397,1 \pm 85,16$ & $213,2 \pm 28,2$ \\
\hline \multirow{2}{*}{ КМЦ (n=13) } & 3 -й день & $5,54 \pm 0,73^{*}$ & $4,95 \pm 0,29^{*}$ & $217,8 \pm 39,4$ & $286,9 \pm 78,2$ & $236,4 \pm 31,7^{*}$ \\
\cline { 2 - 7 } & 7 -й день & $4,68 \pm 0,70$ & $4,46 \pm 0,27$ & $204,0 \pm 33,0$ & $254,1 \pm 73,2$ & $211,6 \pm 29,7$ \\
\hline \multirow{2}{*}{$\begin{array}{l}\text { ВNО-101 } \\
\text { (n=11) }\end{array}$} & 3 -й день & $5,12 \pm 0,78$ & $4,73 \pm 0,38$ & $208,1 \pm 37,1$ & $267,7 \pm 74,1$ & $218,5 \pm 31,3$ \\
\cline { 2 - 7 } & 7 -й день & $3,70 \pm 0,67^{* *}$ & $4,21 \pm 0,28$ & $178,6 \pm 31,2^{* *}$ & $237,4 \pm 71,9$ & $182,4 \pm 33,4$ \\
\hline
\end{tabular}

Пр и меч ан и е: *достоверность различий Р по отношению к норме $(\mathrm{P}<0,05)$; ${ }^{*}-$ по отношению к группе до лечения $(\mathrm{P}<0,05)$.

Применение препаратов мукоактивного действия в комплексе лечения существенно нормализовало исследуемые показатели. Положительная динамика у всех пациентов проявлялась в тенденции к снижению уровней протеолитических ферментов и их ингибиторов по сравнению с показателями до лечения. Самые низ- 
кие уровни ЭПА и ТПА были выявлены в синоназальном секрете больных, принимавших фитониринговый препарат BNO-101 на 7-й день лечения. Уровень ЭПА на 3-й день лечения данным препаратом снизился на 17,2 \% (P<0,001) по сравнению с больными до лечения, но превысил показатель здоровых людей в 1,6 раза. На 7-й день лечения ЭПА снизилась на $67,0 \%(\mathrm{P}<0,001)$ по сравнению с показателями до лечения, но превысила показатель здоровых людей в 1,1 раза. Уровень ТПА на 3-й день снизился на $13,6 \%(\mathrm{P}<0,001)$ по сравнению с показателями до лечения и был в 1,4 раза выше аналогичного показателя здоровых людей. На 7-й день лечения уровень ТПА снизился на 19,03 \% (Р<0,001) по сравнению с больными до лечения и отличался от показателя здоровых людей в 1,2 раза.

Уровень ЭПА в группе больных, принимавших АЦЦ на 3-й день, был незначительно снижен и оставался в 1,8 раза выше, чем у здоровых людей. На 7-й день лечения АЦЦ ЭПА снизилась на 17,2 \% ( $<0,001)$ по сравнению с показателями до лечения, но превышала показатель здоровых людей в 1,6 раза $(\mathrm{P}<0,05)$.

В группе больных, принимавших КМЦ на 3-й день лечения, было выявлено более значительное падение ЭПА. Так, данный показатель снизился на 10,4\% $(\mathrm{P}<0,001)$ по сравнению с ЭПА в секрете больных до лечения и оставался выше показателя здоровых людей в 1,7 раза. Увеличение срока приема КМЦ привело к дальнейшему падению ЭПА, на 7-й день лечения она была на 24,3\% (P<0,001) ниже показателя больных до лечения, но оставалась выше показателя здоровых людей в 1,4 раза. Применение КМЦ на 3-й день лечения не оказало значительного влияния на уровень ТПА. Более выраженный эффект был отмечен на 7-й день приема препарата, в секрете пациентов данной группы уровень ТПА снизился на 14,2\% $(\mathrm{P}<0,05)$ по сравнению с показателем до лечения, но оставался выше показателя нормы на $28,9 \%(\mathrm{P}<0,001)$ или в 1,3 раза.

В синоназальном секрете больных, не получавших в комплексе лечения мукоактивные препараты, на 3-й день лечения была отмечена лишь тенденция к снижению ЭПА по сравнению с показателем до лечения. При этом уровень на 3-й день ЭПА в данной группе превышал показатель здоровых людей в 1,8 раза. На 7-й день лечения произошло более выраженное снижение ЭПА на 21,5 \% ( $<<0,001)$ по сравнению с больными до лечения, но данный показатель превышал показатель здоровых людей в 1,5 раза.

Таким образом, результаты проведенных исследований свидетельствуют о том, что применение мукоактивных препаратов приводит к более быстрой нормализации показателей неспецифических протеиназ и их ингибиторов в синоназальном секрете. Наиболее существенная нормализация изученных показателей происходит при применении препарата BNO-101, который уже на 3-й день лечения не только способствует улучшению общего состояния, носового дыхания, уменьшению ринореи, но и снижает протеолитическую активность на 17,2 \% (P<0,001), а на 7-й день фактически приближает к норме изученные показатели. Можно предположить, что более активная эвакуация синоназального секрета при адекватной мукоактивной терапии способствует ускорению купирования воспалительных проявлений, а следовательно, повышению эффективности лечения острого РС. 


\section{Выводы}

1. Развитие острого катарального риносинусита характеризуется острофазным повышением антитрипсиновой активности в сыворотке крови и существенной активацией неспецифических протеиназ и их ингибиторов в синоназальном секрете.

2. Применение мукоактивных препаратов в комплексе лечения больных с острым катаральным риносинуситом оказывает положительный эффект на течение риносинусита, который характеризуется снижением активности эластазои трипсиноподобных протеиназ, а также нормализацией активности ингибиторов протеиназ в синоназальном секрете.

3. Сравнительный анализ эффективности применения мукоактивных препаратов при лечении острого катарального риносинусита показал, что наиболее значительный эффект отмечен при использовании препарата BNO-101, который на фоне купирования клинических симптомов приводил к снижению показателей неспецифических протеиназ и их ингибиторов до уровня нормы.

\section{Литература}

1. Scheid D. C., Hamm R.M. Acute bacterial rhinosinusitis in adults: part II. Treatment // Am. Fam. Physician. 2004. N 70. P. 1697-1704.

2. Лопатин А. С., Свистушкин В. М. Острый синусит: этиология патогенез, диагностика и принципы лечения: клинические рекомендации. М., 2009. 28 с.

3. Poole M.D. F mathematical therapeutic outcomes model for sinusitis // Otolaryngol. Head Neck Surg. 2004. N 130 (1 Suppl.). P. 46-50.

4. Абдулкеримов Х. Т., Гаращенко Т. И., Кочель В. И., Рязанцев С. В., Свистушкин В. М. Принципы этиопатогенетической терапии острых синуситов: клинические рекомендации / под ред. С. В. Рязанцева. СПб., 2014. 40 с.

5. Solberg L. I., Braun B. L., Fowles J. B., Kind E. A., Anderson R. S., Healey M. L. Care-seeking behavior for upper respiratory infections // J. Fam. Pract. 2000. N 49. P.915-920.

6. Zeiger R. S. Prospects for ancillary treatment of sinusitis in the 1990s // J. Allergy Clin. Immunol. 1992. N 90 (Pt. 3). P. 478-495.

7. Klimek L., Rasp G. Norm values for eosinophil cationic protein in nasal secretions: influence of specimen collection // Clin. Exp. Allergy. 1999. Vol.29. P.367-374.

8. Riechelmann H., Deutschle T., Friemel E., Gross H. J., Bachem M. Biological markers in nasal secretions // Eur. Respir. J.2003. N 21. P.600-605.

9. Кочетова Ю. И., Смольникова Е. В., Антачев А. В., Мокроносова М. А. Определение внеклеточных пероксидаз в назальном секрете больных аллергическим и инфекционным ринитами // Медицинская иммунология. 2004. Т. 6, № 1-2. С. 127-132.

10. Кубышкин А.В., Фомочкина И. И. Эластолитическая активность бронхоальвеолярного лаважа при моделировании воспалительного процесса в легких // Укр. біохім. журнал. 2008. Т. 80, № 1. С. 89-95.

11. Тарасова Г. Д. Секретолитическое лечение при воспалении дыхательных путей в детском возрасте // Лечащий врач. 2000. № 1. С. 35-37.

12. Колб В. Г., Камышников В. С. Справочник по клинической химии. Минск, 1982. С. 290-291.

Для цитирования: Завалий А. А., Кубышкин А. В., Жукова А. А. Влияние мукоактивных препаратов на состояние неспецифических протеиназ и их ингибиторов у больных острым катаральным риносинуситом // Вестник СПбГУ. Серия 11. Медицина. 2016. Вып. 4. С. 55-61.

DOI: $10.21638 / 11701 /$ spbu11.2016.405

\section{References}

1. Scheid D. C., Hamm R. M. Acute bacterial rhinosinusitis in adults: part II. Treatment. Am. Fam. Physician, 2004, no. 70, pp. 1697-1704.

2. Lopatin A.S., Svistushkin V.M. Ostryi sinusit: etiologiia patogenez, diagnostika i printsipy lecheniia: klinicheskie rekomendatsii [Acute sinusitis: etiology, pathogenesis, diagnostics and principles of treatment: clinical recommendations]. Moscow, 2009, 28 p. (In Russian) 
3. Poole M. D. F mathematical therapeutic outcomes model for sinusitis. Otolaryngol. Head Neck Surg., 2004, no. 130 (Suppl. 1), pp. 46-50.

4. Abdulkerimov Kh. T., Garashchenko T. I., Koshel' V. I., Svistushkin V. M. Printsipy etiopatogeneticheskoi terapii ostrykh sinusitov: klinicheskie rekomendatsii [Principles of etiopathogenetic therapy of acute sinusitises: clinical recommendations]. Ed. by S. V. Ryazantsev. St. Petersburg, 2014, 40 p. (In Russian)

5. Solberg L. I., Braun B. L., Fowles J. B., Kind E. A., Anderson R. S., Healey M. L. Care-seeking behavior for upper respiratory infections. J. Fam. Pract., 2000, no. 49, pp. 915-920.

6. Zeiger R. S. Prospects for ancillary treatment of sinusitis in the 1990s. J. Allergy Clin. Immunol., 1992, no. 90 (Pt. 3), pp. 478-495.

7. Klimek L., Rasp G. Norm values for eosinophil cationic protein in nasal secretions: influence of specimen collection. Clin. Exp. Allergy., 1999, vol. 29, pp. 367-374.

8. Riechelmann H., Deutschle T., Friemel E., Gross H.J., Bachem M. Biological markers in nasal secretions. Eur. Respir. J., 2003, no. 21, pp. 600-605.

9. Kochetova Yu. I., Smol'nikova E. V., Antashev A. V., Mokronosova M. A. Opredelenie vnekletochnykh peroksidaz $\mathrm{v}$ nazal'nom sekrete bol'nykh allergicheskim i infektsionnym rinitami [Determination of extra cellularer oxidasesin the nasal discharge of patients with allergic and infectious rhinitides]. Meditsinskaia immunologiia [Medical Immunology], 2004, vol. 6, no. 1-2, pp. 127-132. (In Russian)

10. Kubyshkin A.V., Fomochkina I. I. Elastoliticheskaia aktivnost' bronkhoal'veoliarnogo lavazha pri modelirovanii vospalitel'nogo protsessa v legkikh [Elastolyticactivity of bronchoalveolar lavage in modeling of the inflammatory processin lungs]. Ukr. biokhim. zhurnal [Ukr. Biochem. Journal], 2008, vol. 80, no. 1, pp. 89-95. (In Russian)

11. Tarasova G.D. Sekretoliticheskoe lechenie pri vospalenii dykhatel'nykh putei v detskom vozraste [Mucolytic treatment of respiratory tract inflammation in children]. Lechashchii vrach [Attending Physician], 2000, no. 1, pp. 35-37. (In Russian)

12. Kolb V.G., Kamyshnikov V.S. Spravochnik po klinicheskoi khimii [Guidelineson Clinical Chemistry]. Minsk, 1982, pp. 290-291. (In Russian)

For citation: Zavalii A. A., Kubyshkin A. V., Zhukova A. A. The influence of mucoactive agents on the state of non-specific proteinases and their inhibitors in patients with acute catarrhal rhinosinusitis. Vestnik SPbSU. Series 11. Medicine, 2016, issue 4, pp. 55-61. DOI: 10.21638/11701/spbu11.2016.405

Статья поступила в редакцию 13 мая 2016 г.

Контактная информация:

Завалий Антон Алексеевич - аспирант; antonzavalii@gmail.com

Кубыикин Анатолий Владимирович - доктор медицинских наук, профессор; anatoly_diltek@mail.ru

Жукова Анна Александровна - кандидат биологических наук; anna_crimea@mail.ru

Zavalii Anton A. - Postgraduate; antonzavalii@gmail.com

Kubyshkin Anatoliy V. _- DM, Professor; anatoly_diltek@mail.ru

ZhukovaAnna A. - PhD; anna_crimea@mail.ru 